\title{
Additional changes to taxonomy ratified in a special vote by the International Committee on Taxonomy of Viruses (October 2018)
}

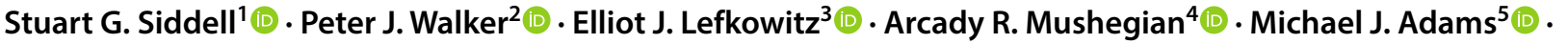

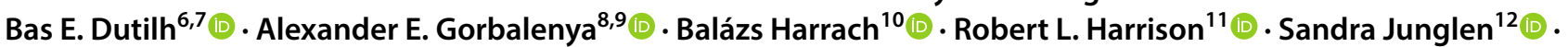

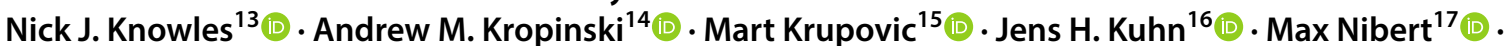

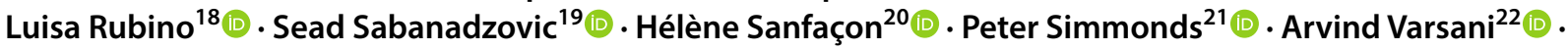 \\ Francisco Murilo Zerbini ${ }^{23}$ (D) . Andrew J. Davison ${ }^{24}$
}

Published online: 20 January 2019

(c) This is a U.S. government work and its text is not subject to copyright protection in the United States; however, its text may be subject to foreign copyright protection 2019

\section{Abstract}

This article reports the changes to virus taxonomy approved and ratified by the International Committee on Taxonomy of Viruses (ICTV) in October 2018. Of note, the ICTV has approved, by an absolute majority, the creation of additional taxonomical ranks above those recognized previously. A total of 15 ranks (realm, subrealm, kingdom, subkingdom, phylum, subphylum, class, subclass, order, suborder, family, subfamily, genus, subgenus, and species) are now available to encompass the entire spectrum of virus diversity. Classification at ranks above genus is not obligatory but can be used by the authors of new taxonomic proposals when scientific justification is provided.

Handling Editor: Tim Skern.

Electronic supplementary material The online version of this article (https://doi.org/10.1007/s00705-018-04136-2) contains supplementary material, which is available to authorized users.

Arcady R. Mushegian

mushegian2@gmail.com

Stuart G. Siddell

stuart.siddell@bristol.ac.uk

Peter J. Walker

Peter.Walker@uq.edu.au

Elliot J. Lefkowitz

elliotl@uab.edu

Michael J. Adams

mike.adams.ictv@gmail.com

Bas E. Dutilh

bedutilh@gmail.com

Alexander E. Gorbalenya

a.e.gorbalenya@lumc.nl

Balázs Harrach

harrach.balazs@agrar.mta.hu

Robert L. Harrison

robert.1.harrison@ars.usda.gov

\author{
Sandra Junglen \\ sandra.junglen@charite.de \\ Nick J. Knowles \\ nick.knowles@ pirbright.ac.uk \\ Andrew M. Kropinski \\ phage.canada@gmail.com \\ Mart Krupovic \\ mart.krupovic@pasteur.fr \\ Jens H. Kuhn \\ kuhnjens@mail.nih.gov \\ Max Nibert \\ mnibert@hms.harvard.edu \\ Luisa Rubino \\ luisa.rubino@cnr.it \\ Sead Sabanadzovic \\ ssabanadzovic@entomology.msstate.edu \\ Hélène Sanfaçon \\ helene.sanfacon@canada.ca
}




\section{Introduction}

Changes to virus taxonomy (the universal scheme of virus classification of the International Committee on Taxonomy of Viruses [ICTV]) take place annually and are the result of a multi-stage process. In accordance with the ICTV Statutes (http://ictv.global/statutes.asp), proposals submitted to the ICTV Executive Committee (EC) undergo a review process that involves input from the ICTV Study Groups (SGs) and Subcommittees (SCs), other interested virologists, and the EC. After final approval by the EC, proposals are presented for ratification to the full ICTV membership by publication on the ICTV website (http://ictv.global) followed by an electronic vote.

Peter Simmonds

peter.simmonds@ndm.ox.ac.uk

Arvind Varsani

arvind.varsani@asu.edu

Francisco Murilo Zerbini

zerbini@ufv.br

Andrew J. Davison

andrew.davison@glasgow.ac.uk

1 Faculty of Life Sciences, School of Cellular and Molecular Medicine, University of Bristol, University Walk, Bristol BS8 1TD, UK

2 School of Biological Sciences, The University of Queensland, St Lucia, QLD 4072, Australia

3 Department of Microbiology, University of Alabama at Birmingham (UAB), BBRB 276, 845 19th ST South, Birmingham, AL 35294-2170, USA

4 Division of Molecular and Cellular Biosciences, National Science Foundation, 2415 Eisenhower Avenue, Alexandria, VA 22314, USA

5 Stevenage, UK

6 Theoretical Biology and Bioinformatics, Department of Biology, Utrecht University, Padualaan 8, Room Z-509, $3584 \mathrm{CH}$ Utrecht, The Netherlands

7 Centre for Molecular and Biomolecular Informatics, Radboud University Medical Center (Radboudumc), Geert Grooteplein 26, 6525 GA Nijmegen, The Netherlands

8 Department of Medical Microbiology, Leiden University Medical Center, E4-P, rm. E4-72, P. O. Box 9600, 2300 RC Leiden, The Netherlands

9 Faculty of Bioengineering and Bioinformatics, Lomonosov Moscow State University, 119899 Moscow, Russia

10 Institute for Veterinary Medical Research, Centre for Agricultural Research, Hungarian Academy of Sciences, Hungária krt. 21, Budapest 1143, Hungary

11 Invasive Insect Biocontrol and Behavior Laboratory, USDA-ARS, 10300 Baltimore Avenue, Bldg 007 BARC-West, Beltsville, MD 20705, USA
Nine proposals that were discussed at the EC meeting in July 2017 (Singapore) and subsequently at the EC meeting in July 2018 (Washington, DC, USA) [1-9] were approved by the EC and then ratified in a supplemental vote. The proposals were made publicly available on the ICTV website in August 2018, and a list of them was then emailed on August 30, 2018 to the 156 members of ICTV, i.e., EC Members, Life Members, ICTV Subcommittee Members (including the SG chairs) and ICTV National Representatives. Following this, members were requested to vote on whether to ratify the proposals, with a closing date of October 7, 2018. Since the processing of these proposals overlapped the end of the 2014-2017 EC tenure and the

12 Institute of Virology, Corporate Member of Free University Berlin, Charité-Universitätsmedizin, Humboldt-University Berlin, and Berlin Institute of Health, Berlin, Germany

13 The Pirbright Institute, Ash Road, Pirbright, Surrey GU24 0NF, UK

14 Departments of Food Science, and Pathobiology, University of Guelph, Guelph, Ontario N1G 2W1, Canada

15 Department of Microbiology, Institut Pasteur, 25 rue du Dr Roux, 75015 Paris, France

16 NIH/NIAID/DCR Integrated Research Facility at Fort Detrick (IRF-Frederick), B-8200 Research Plaza, Fort Detrick, Frederick, MD 21702, USA

17 Department of Microbiology and Immunobiology, Harvard Medical School, 77 Ave Louis Pasteur, Boston, MA 02115, USA

18 Istituto di Protezione Sostenibile delle Piante, CNR, UOS Bari, Via Amendola 165/A, 70126 Bari, Italy

19 Department of Biochemistry, Molecular Biology, Entomology and Plant Pathology, Mississippi State University, 100 Old Hwy 12 Mail Stop 9775, Starkville, MS 39762, USA

20 Summerland Research and Development Centre, Agriculture and Agri-Food Canada, 4200 Highway 97, Summerland, British Columbia VOH 1Z0, Canada

21 Nuffield Department of Experimental Medicine, University of Oxford, Peter Medawar Building, South Parks Road, Oxford OX1 3PS, UK

22 School of Life Sciences, The Biodesign Center for Fundamental and Applied Microbiomics, Center for Evolution and Medicine, Arizona State University, P.O. Box 874701, Tempe, AZ 85287-4701, USA

23 Departamento de Fitopatologia/BIOAGRO, Universidade Federal de Viçosa, Viçosa, MG 36570-900, Brazil

24 MRC-University of Glasgow Centre for Virus Research, Sir Michael Stoker Building, 464 Bearsden Road, Glasgow G61 1QH, UK 
Table 1 Summary of taxonomic changes approved in October 2018

\begin{tabular}{lrlccr}
\hline & \multicolumn{3}{c}{ Taxonomic Change } & \\
\cline { 2 - 5 } Rank & New & Abolished & Moved & Renamed & Total $^{\text {a }}$ \\
\hline Phylum & 1 & 0 & 0 & 0 & 1 \\
Subphylum & 2 & 0 & 0 & 0 & 2 \\
Class & 6 & 0 & 0 & 0 & 6 \\
Order & 5 & 0 & 2 & 0 & 14 \\
Suborder & 7 & 0 & 0 & 0 & 7 \\
Family & 15 & 3 & 21 & 0 & 143 \\
Subfamily & 18 & 0 & 2 & 1 & 64 \\
Genus & 50 & 7 & 73 & 3 & 846 \\
Subgenus & 59 & 0 & 0 & 0 & 59 \\
Species & 107 & 2 & 504 & 43 & 4,958 \\
\hline
\end{tabular}

${ }^{a}$ Total numbers of taxa now recognized, as reported in the ICTV Master Species List

start of the 2017-2020 EC tenure, members of both ECs constitute the authorship of this article.

\section{Changes to virus taxonomy: taxa and nomenclature}

The 156 members of the ICTV were contacted by e-mail and asked to vote on the ratification of the nine proposals. All nine proposals [1-9] were ratified by ICTV members. Proposal 2017.005G, introducing the additional ranks [1], was ratified by 99 votes in favor and 6 votes against. Voting on the remaining eight proposals, each of which utilizes some of the new taxonomy ranks, was contingent on ICTV members voting in favor of proposal 2017.005G, and each of these proposals received from 83 to 86 votes. A summary of the individual proposals is provided in Table 1, and the entire revised taxonomy reflecting the approved changes is shown in Supplementary file 1, with the new taxa indicated by bold type. Each proposal is cited and listed in the References to acknowledge the authors' efforts and to provide links to the specific proposal as coded on the ICTV website. These documents remain available for those who wish to see the full details of the proposals.

The introduction of the additional ranks permitted in virus taxonomy necessitates several changes in the ICTV Code. The proposed changes to the Code, approved by the EC, are posted at http://ictv.global/code.asp and will be submitted for ratification by ICTV in early 2019 .

\section{Conclusion}

All nine proposals submitted to ratification were ratified by an absolute majority of the ICTV, and the changes proposed are now part of official ICTV taxonomy. An up-to-date list of all approved taxa can be found on the ICTV online website: $\mathrm{http}: / / \mathrm{ictv}$.global/msl.htm. The remaining taxonomic proposals approved at the EC meeting in July 2018 (Washington, DC, USA) will be offered to the ICTV for ratification in early 2019.

\section{Compliance with ethical standards}

Conflict of interest The authors declare no conflicts of interest. A.R.M. is a Program Director at the U.S. National Science Foundation (NSF); the statements and opinions expressed herein are made in a personal capacity and do not constitute endorsement by NSF or the government of the United States. Mention of trade names or commercial products in this publication is solely for the purpose of providing specific information and does not imply recommendation or endorsement by the U.S. Department of Agriculture. USDA is an Equal Opportunity Provider and Employer. The content of this publication does not necessarily reflect the views or policies of the US Department of Health and Human Services or of the institutions and companies affiliated with the authors. This work was supported in part through Battelle Memorial Institute's prime contract with the US National Institute of Allergy and Infectious Diseases (NIAID) under Contract No. HHSN272200700016I (J.H.K.). N.J.K. is partially supported by core funding provided by the Biotechnology and Biological Sciences Research Council, UK. B.E.D. is supported by Netherlands Organization for Scientific Research (NWO) Vidi grant 864.14.004. B.H. is partially supported by National Research, Development and Innovation Office - NKFIH, NN128309. A.E.G. is partially supported by EU project EVAg 653316 and the Leids Universiteits Fonds. A.J.D. is supported by the Medical Research Council (MC_UU_12014/3). S.S. acknowledges partial support from Mississippi Agricultural and Forestry Experiment Station (MAFES), Mississippi State University.

Human and animal rights statement None of the work reported involved research on human participants or animals. All authors have contributed to this work and agreed to its publication.

\section{References}

1. Gorbalenya AE, Krupovic M, Mushegian A, Kropinski AM, Siddell S, Varsani A, Kuhn JH (2017) Proposal 2017.005G.A.v1. Increasing the number of ranks available in virus taxonomy. https ://talk.ictvonline.org/ICTV/proposals/2017.005G.A.v1.Additional TaxonomyRanks.docx. Accessed 15 Oct 2018 (Correspondence: stuart.siddell@bristol.ac.uk)

2. Wolf Y, Krupovic M, Zhang YZ, Maes P, Dolja V, Koonin EV, Kuhn JH (2018) Proposal 2017.016 M.A.v2. Megataxonomy of negative-sense RNA viruses. https://talk.ictvonline.org/ICTV/ proposals/2017.006M.R.Negarnaviricota.zip. Accessed 15 Oct 2018 (Correspondence: kuhnjens@mail.nih.gov)

3. Maes P, Alkhovsky S, Beer M, Briese T, Buchmeier MJ, Calisher $\mathrm{CH}$, Charre R, Ryong Choi I, Clegg CS, de la Torre JC, DeRisi JL, Digiaro M, Ebihara H, Emonet S, Elbeaino T, Gonzalez J-P, Haenni A-L, Jain R, Jonson G, Junglen S, Kormelink R, Lambert 
A, Lukashevich IS, Martelli GP, Mielke-Ehret N, Muehlbach H-P, Nunes MRT, Peters CJ, Plyusnin A, Radoshitzky SR, Romanowski V, Salvato MS, Sasaya T, Schmaljohn C, Shirako Y, Stenglein MD, Tesh RB, Wei T, Yeh S-D, Zhang Y, Zhou X, Kuhn JH (2018) Proposal 2017.012 M.A.v2. Taxonomic expansion and reorganization of the order Bunyavirales. https://talk.ictvonline .org/ICTV/proposals/2017.012M.R.Bunyavirales.zip. Accessed 15 Oct 2018 (Correspondence: kuhnjens@mail.nih.gov)

4. Maes P, Song T, Stenglein, Paweska J, Song Q, Ye G, Zhang, Y, Kuhn JH, Dietzgen RG, Easton AJ, Kurath G, Nowotny N, Rima BK, Rubbenstroth D, Vasilakis N, Walker P, Domier LL, Ghedin E, Jiang D, Wang, D (2018) Proposal 2017.016 M. Av1. Taxonomic expansion and reorganization of the order Mononegavirales. https://talk.ictvonline.org/ICTV/propo sals/2017.016M.R.Mononegavirales.zip. Accessed 15 Oct 2018 (Correspondence: kuhnjens@mail.nih.gov)

5. Vanmechelen B, Vergote V, Laenen L, Kuhn JH, Maes P (2018) Proposal 2017.001S.A.v1. One new subfamily, genus and species in the family Arteriviridae (Nidovirales). https://talk.ictvo nline.org/ICTV/proposals/2017.001S.A.v1.Crocarterivirinae.zip. Accessed 15 Oct 2018 (Correspondence: piet.maes@kuleuven. be)

6. Brinton MA, Gulyaeva A, Balasuriya UBR, Dunowska M, Faaberg KS, Goldberg T, Leung FC, Nauwynck HJ, Snijder EJ, Stadejek T, Gorbalenya AE (2018) Proposal 2017.012S.A.v1. Expansion of the rank structure of the family Arteriviridae and renaming its taxa. https://talk.ictvonline.org/ICTV/proposals/2017.001S.012017S.R.Nidovirales.zip. Accessed 15 Oct 2018 (Correspondence: A.E.Gorbalenya@lumc.nl)
7. Ziebuhr J,Baric RS, Baker S, de Groot RJ, Drosten C, Gulyaeva, Haagmans BL, Neuman BW, Perlman S, Poon LLM, Sola I, Gorbalenya AE (2018) Proposal 2017.013S.A.v1. Reorganization of the family Coronaviridae into two families, Coronaviridae (including the current subfamily Coronavirinae and the new subfamily Letovirinae) and the new family Tobaniviridae (accommodating the current subfamily Torovirinae and three other subfamilies), revision of the genus rank structure and introduction of a new subgenus rank. https://talk.ictvonline.org/ICTV/propo sals/2017.001S.012-017S.R.Nidovirales.zip. Accessed 15 Oct 2018 (Correspondence: A.E.Gorbalenya@lumc.nl)

8. Gorbalenya AE, Brinton MA, Cowley J, de Groot R, Gulyaeva A, Lauber C, Neuman B, Ziebuhr J (2018) Proposal 2017.014S. v1. Establishing taxa at the ranks of subfamily, genus, subgenus and species in six families of invertebrate nidoviruses. https://talk.ictvonline.org/ICTV/proposals/2017.001S.012017S.R.Nidovirales.zip. Accessed 15 Oct 2018 (Correspondence: A.E.Gorbalenya@lumc.nl)

9. Gorbalenya AE, Brinton MA, Cowley J, de Groot R, Gulyaeva A, Lauber C, Neuman B, Ziebuhr J (2018) Proposal 2017.015S.A.v1. Reorganization and expansion of the order Nidovirales at the family and sub-order ranks. https://talk.ictvonline.org/ICTV/propo sals/2017.001S.012-017S.R.Nidovirales.zip. Accessed 15 Oct 2018 (Correspondence: A.E.Gorbalenya@lumc.nl)

Publisher's Note Springer Nature remains neutral with regard to jurisdictional claims in published maps and institutional affiliations. 